\title{
DO MEDIAL PIVOT KINEMATICS CORRELATE WITH PATIENT-REPORTED OUTCOMES AFTER TOTAL KNEE ARTHROPLASTY?
}

\author{
Lucian C. Warth, $\mathrm{MD}^{1,2}$ \\ Marshall K. Ishmael, BS ${ }^{2}$ \\ Evan R. Deckard, BS ${ }^{2}$ \\ Mary Ziemba-Davis, BA $^{2}$ \\ R. Michael Meneghini, MD ${ }^{1,2}$
}

${ }^{1}$ Indiana University School of Medicine, Department of Orthopaedic Surgery, 1120 W. Michigan Street, Room 600, Indianapolis, IN 46202

${ }^{2}$ Indiana University Health Physicians Orthopedics and Sports Medicine, IU Health Saxony Hospital, 13100 East $136^{\text {th }}$ Street, Suite 2000, Fishers, IN 46037

Corresponding Author:

Lucian C. Warth, MD

Indiana University Health Physicians Orthopedics and Sports Medicine

Indiana University School of Medicine, Department of Orthopaedic Surgery

$13100136^{\text {th }}$ Street

Suite 2000

Fishers, IN 46037

Phone: 317-688-5980

lcwarth@iuhealth.org

This is the author's manuscript of the article published in final edited form as:

Warth, L. C., Ishmael, M. K., Deckard, E. R., Ziemba-Davis, M., \& Meneghini, R. M. (2017). Do Medial Pivot Kinematics Correlate with Patient-Reported Outcomes after Total Knee Arthroplasty? The Journal of Arthroplasty. https://doi.org/10.1016/j.arth.2017.03.019 


\section{DO MEDIAL PIVOT KINEMATICS CORRELATE WITH PATIENT-REPORTED OUTCOMES AFTER TOTAL KNEE ARTHROPLASTY?}

\section{Abstract}

Introduction: Many total knee arthroplasty (TKA) implants are designed to facilitate a medial pivot kinematic pattern. The purpose of this study was to determine whether intraoperative medial pivot kinematic patterns are associated with improved patient outcomes.

Methods: Retrospective review of consecutive primary TKAs with a modern implant design was performed. Sensor-embedded tibial trials determined kinematic patterns intraoperatively. The center of rotation $(\mathrm{COR})$ was identified on medial and lateral condyles from $0^{\circ}$ to $90^{\circ}$ and from $0^{0}$ to terminal flexion, and designated medial-pivot or non-medial pivot based on accepted criteria. Patient-reported outcomes were measured preoperatively and at minimum one-year follow-up.

Results: The analysis sample consisted of 141 TKAs after exclusions for potential confounds (53) and loss to minimum one-year follow-up (9). Seventy-five percent of patients were female. Mean age and median BMI were 63.7 years and $33.8 \mathrm{~kg} / \mathrm{m} 2$, respectively. Forty-percent of TKAs had a medial pivot kinematic pattern from 0 to $90^{\circ}$ and $0^{\circ}$ to terminal flexion. A medial pivot pattern was greatest with cruciate-retaining compared to PCL-sacrificing TKAs $(p \leq 0.0150)$. Regardless of bearing type, minimum one-year Knee Society objective, satisfaction, function, walking pain, stair pain and UCLA Activity Level did not differ based on medial vs. non-medial pivot patterns from 0 to $90^{0}$ ( $\left.p \geq 0.292\right)$. Improvement in outcomes largely did not differ based on pivot type, although for patients with PCLsacrificing implants, there were trends for greater median improvement in Knee Society objective (46 vs. 31.5 points, $p=0.057$ ) and satisfaction ( 23 vs. 14 points, $p=0.067)$ scores in medial pivot knees. Outcomes did not vary based on pivot classifications from $0^{0}$ to terminal flexion. 
25 Discussion: A medial pivot pattern may not govern clinical success based on intraoperative kinematics

26 and modern outcome measures. Further research is warranted to determine if a particular kinematic

27 pattern promotes optimal clinical outcomes after TKA.

28 Keywords: total knee arthroplasty, medial pivot, kinematics, patient-reported outcomes 


\section{Introduction}

Total knee arthroplasty (TKA) is a well-accepted procedure for the treatment of end stage knee arthritis. The procedure has proven to be exceptionally reliable in terms of implant longevity, with 20year revision free survival rates between 70.9\%-91.0\%.[1-11] Unfortunately, achieving a comparable level of subjective clinical success has proven to be elusive. A host of reports evaluating patient reported outcomes after TKA quote up to $20 \%$ of patients are not satisfied, often citing continued pain, stiffness, or an 'unnatural' feel to the joint.[12-14]

Traditional surgical principles of TKA have focused on re-establishing limb alignment and ligament balance during surgery. Bone cuts and soft tissues releases are combined to correct tibiofemoral malalignment, balance extension and flexion gaps, enhance patellar tracking, and optimize range of motion. Variations in ligament balance and tension logically affect knee kinematics and furthering the lack of predictability is that ligament balance is subjective, surgeon specific, and highly variable. Understandably, limb alignment and ligament balance as drivers of outcome have overshadowed kinematics, however, this has been due to a lack of readily available tools to quantify intraoperative and post-operative kinematics, as well as insufficient knowledge regarding the complexity of kinematic patterns in native and TKA knees.

Intuitively, a well done TKA would restore normal knee kinematics and thereby function. The potential of new technology to provide intra-operative feedback during TKA including computer guidance, robotic assistance, and digital sensors in tibial trials has led to resurgent interest in kinematics. Understanding how alignment and balance relates to kinematics and subsequently how this correlates patient with satisfaction remains in its infancy.

Dennis et al found that $60 \%$ of patients with normal knees presented with a medial pivot pattern during gait, and $80 \%$ of patients with normal knees presented with a medial pivot location during a deep knee bend.[15] While a number of modern TKA implants are theoretically designed to facilitate or 
guide a medial-based kinematic pattern during knee motion, [16-20] there is a dearth of literature evaluating how consistently surgeons hit the kinematic target, and if that goal yields improvements clinically. Recently, Nishio and colleagues[21] analyzed intraoperative kinematic patterns from 0-90 degrees in posteriorly stabilized TKAs using a computed tomography (CT)-based navigation system and identified significantly better subjective outcomes and knee flexion angles after TKA in patients with a medial pivot kinematic pattern when compared to non-medial pivot knees.

The purpose of the present study was to determine if intraoperative kinematic patterns provided by digital sensor technology correlate with postoperative function, pain, and satisfaction at minimum one-year follow-up after primary TKA. We hypothesized that TKAs which demonstrated a medial-based kinematic pattern intraoperatively would be associated with improved patient-reported outcomes postoperatively.

\section{Methods}

After institutional review board approval was obtained, a retrospective review of a prospectively collected database of consecutive primary TKAs was undertaken. Procedures were performed between April 2013 and April 2014 by two board-certified arthroplasty surgeons at a single institution. Of the original 203 TKAs, 53 were excluded due to unavailability of the required size of the Verasense ${ }^{\mathrm{TM}}$ device (31), device malfunction (5), atypical hardware creating additional soft tissue trauma (5), surgery performed at a non-study hospital (4), unresurfaced patella (1), early revision (2), significant medical complication affecting outcomes (2), death unrelated to the index TKA (1), and statistically outlying intraoperative sensing device values (2). The two cases excluded for revision resulted from infection and aseptic tibial component loosening after a fall. Of the remaining 150 TKAs, nine $(0.6 \%)$ were lost to minimum one-year follow-up.

A median parapatellar approach was used for all procedures. Standard coronal plane tibial and femoral bone cuts were made with computer-aided navigation. One knee arthroplasty system 
(Triathlon®; Stryker, Inc., Mahwah, NJ) was used in all patients. One surgeon used cruciate-retaining femoral components with CR or CS/anterior lipped inserts and one surgeon routinely sacrificed the PCL, and used posterior stabilized femoral components or a cruciate-retaining femoral component with CS/anterior lipped inserts based on femoral component size.

In each case, sensor-embedded tibial trials (Verasense ${ }^{\mathrm{TM}}$; OrthoSensorTM, Sunrise, FL) were used to quantify tibio-femoral contact points and medial and lateral compartment forces and following implantation of a TKA using traditional balancing techniques based on manual and tactile surgeon judgment. During acquisition of tibial trial sensor data, the foot was held at the heel without any specific rotational constraint with light support underneath the leg as the knee was taken through a range of motion by flexing the leg at the hip joint. This is the standard methodology utilized in previous studies by developers of the technology $[22,23]$ and is consistent with instructions provided by the industry representative present in the initial series of patients to ensure proper use and operation of the tibial insert sensor.

The measure of interest in this study -- tibio-femoral contact point measurements -- were calculated and recorded for each patient at terminal extension, and at $45^{\circ}, 90^{\circ}$, and terminal flexion. Measurements from terminal extension to $90^{\circ}$ of flexion were averaged to generate best estimates of the center of rotation $\left(\mathrm{COR} 0^{\circ}\right.$ to $\left.90^{\circ}\right)$. Measurements from terminal extension to terminal flexion also were averaged to generate a second best estimate of the $\mathrm{COR}\left(0^{\circ}\right.$ to terminal flexion). Patient age, sex, and body mass index (BMI); and femoral implant type (cruciate-retaining with CR insert, cruciate retaining with CS/anterior lipped insert, or posterior stabilized) were recorded.

\section{Data Extraction}

Four images per patient were cropped from the tibial sensor trial video output data, one for each of the flexion angles $\left(0^{\circ}, 45^{\circ}, 90^{\circ}\right.$, terminal flexion). Each image displayed a visual representation of tibial sensor trial insert with a graphical user interface for the compartmental compressive contact forces 
and associated contact location on the medial and lateral tibial plateau as shown in Figure 1. The cropped image shown in Figure 2 was imported into MATLAB ${ }^{\circledR}$ (The Mathworks, Natick, MA) after alterations conducted in Microsoft Paint ${ }^{\circledR}$ (Microsoft, Redmond, WA) to determine the exact position of the force contact points by a custom image processing program. The custom image processing program operated based on detecting color differences within the cropped image. Potential error in calculations by MATLAB® was eliminated by "blacking out" all unnecessary color from the image. The only remaining items from the original cropped image were the contact points (Figure 2). The exact placement of the dot within the contact point was irrelevant due to the entire dot being engulfed when the image was processed. The dot was placed to create a larger color difference to allow the program to easily detect the condylar contact points. Next, a white dot was placed at the center of the graphic user interface to create an origin for that particular image. To eliminate this potential for error, the graphic user interface inherently had a circle at the center of each implant which could be used as reference to the origin and allow an accurate placement of the white dot for each image (Figure 2).

The centroid of each isolated contact point was calculated with built-in MATLAB® ${ }^{\circ}$ commands from the image processing toolbox. Each image was appropriately scaled based on the screen size (in pixels) and manufacturer specified dimensions (in $\mathrm{mm}$ ) of that particular trial tibial insert size. All screen resolutions were constant throughout COR measurements (1280x1024 pixels). A universal origin was determined based on the center of the tibial sensor trial and remained constant throughout data extraction for each patient and different implant sizes. The delta values between the force contact points and the universal origin were then calculated and exported to an Excel (Microsoft Corporation, Redmond, WA) spreadsheet for further analyses via MATLAB®. Other calculated values extracted to the Excel spreadsheet from MATLAB® were the implant's center of rotation, pivot type and pivot angle. Pairs of contact points for each measurement were plotted as shown in Figure 3 together for visual representation of contact locations on the tibial surface. Vector equations created lines between 
the two tibio-femoral contact points on the medial and lateral sides and were used to calculate the center of rotation between measurement positions. As noted previously, CORs were calculated based on vectors from extension to $90^{\circ}$ of flexion similar to Nishio et al.[21] and from extension to terminal flexion. Each patient was assigned a kinematic pattern- medial or non-medial - based on the location of the center of rotation in these ranges of motion. Regardless of laterality, a COR of 0 is located in the center of the tibial trial insert. To the sides of this 0 point, $5 \mathrm{~mm}$ to $1000 \mathrm{~mm}$ (for the left leg) and -5 $\mathrm{mm}$ to $-1000 \mathrm{~mm}$ (for the right leg) were identified as the areas in which a COR value could reliably be classified as either a medial or lateral pivot depending on the laterality of the knee. If the COR value was less than $5 \mathrm{~mm}$ in the left knee or greater than $-5 \mathrm{~mm}$ in the right knee, it was classified as a central pivot. If it was greater than $1000 \mathrm{~mm}$ in the left knee or less than $-1000 \mathrm{~mm}$ in the right knee, it was classified as a translating pivot.

\section{Patient-Reported Outcomes}

Patient-reported outcomes were evaluated preoperatively and at minimum one-year postoperatively utilizing the new Knee Society Scoring System.[24, 25] The Knee Society Scoring consists of validated objective and subjective scores. The Knee Society objective score, denoted “KSSO" in this manuscript, evaluates knee pain (25 points), alignment (25 points), stability (25 points), and range-of-motion (ROM) (25 points) for a total possible score of 100. Total possible points for the subjective scores, satisfaction component (denoted "KSSS" in this manuscript) and functional component (denoted "KSSF" in this manuscript), are 40 points and 100 points, respectively. Individual items from the Knee Society questionnaire, including pain with level walking and pain with stairs or inclines (both scored $0=$ none to $10=$ severe) and the question "Does this knee feel normal to you?" (always, sometimes, never) also are reported. The University of California Los Angeles (UCLA) Activity Level Score $[26,27]$ ask patients to choose their highest level of current activity, ranging from 
0 (Wholly Inactive: dependent upon others, cannot leave residence) to 10 (Regularly participate in impact sports such as jogging, tennis, skiing, acrobatics, ballet, heavy labor, or backpacking).

\section{Statistical Analysis}

Minitab 17 (State College, PA) was used for data analysis. Anderson-Darling (AD) tests using alpha $\leq 0.05$ revealed that, among all independent and dependent continuous variables, only patient age was normally distributed. Student's t-test was used to compare patient age in medial and non-medial pivot knees. Non-normally distributed continuous variables were compared with the Mann-Whitney (W) test adjusted for ties. Pearson's Chi-Square $\left(\mathrm{X}^{2}\right)$ test was used to test independence among categorical variables, with Fishers Exact test $p$ values reported for 2 x 2 contingency tables.

\section{Results}

Medial and Non-Medial Pivot Based on the Average COR from $0^{\circ}$ to $90^{\circ}$ Flexion

Pivot type could not be determined based on the COR from $0^{\circ}$ to $90^{\circ}$ for two TKA's. For the remaining 139 knees, the average center of rotation in the 90-degree flexion arc ranged from -324.03 to $605.81 \mathrm{~mm}$ with positive signifying the medial side. Medial pivot knees comprised $40 \%(55 / 139)$ of the total sample.

Pivot classification did not differ based on patient sex $\left(75 \%\right.$ female, $\left.X^{2}=0.739, p=0.428\right)$, median BMI $\left(32.9 \mathrm{~kg} / \mathrm{m}^{2}, \mathrm{~W}=3723.5, p=0.587\right)$, or median length of follow-up $(19.6$ months, $\mathrm{W}=$ $3947.5, p=0.676$ ). There was a trend for patients with medial pivot knees (mean 65.7 years, SD 9.4) to be slightly older than those with non-medial pivot knees (62.4 years, SD 10.2) $(\mathrm{t}=1.92, p=0.06)$. Forty-nine percent of knees with CR/CS anterior-lipped implants were classified as medial pivots compared to $28 \%$ of knees with PS implants $\left(X^{2}=6.223, p=0.015\right)$. Separate analyses were performed based on implant type to control for the interaction between pivot and implant type.

As shown in Table 1, for patients with CR/CS anterior-lipped implants and those with PS implants, minimum one-year KSSO, KSSS, KSSF, UCLA Activity Level, and walking and stair pain 
did not statistically differ based on medial vs. non-medial pivot type ( $p=0.292$ to 0.951 ). Preoperative to postoperative improvement in these outcomes also largely did not differ based on pivot type, although for patients with PS implants, there were trends for greater median improvement in KSSO (46 vs. 31.5 points, $p=0.057$ ) and KSSS (23 vs. 14 points, $p=0.067)$ in medial pivot knees.

Examination of the Knee Society question "Does this knee feel normal to you" revealed no statistically significant differences based on medial and non-medial pivot classification within each of the two implant types (Figure 4). Fifty-six percent of patients with CR/CS anterior-lipped implants and medial pivot knees reported that their knee always felt normal compared to $47 \%$ of patients with CR/CS anterior-lipped implants and non-medial pivot knees $\left(\mathrm{X}^{2}=4.659, p=0.097\right)$. Among patients with PS implants, $47 \%$ and $36 \%$ of those with medial pivot and non-medial pivot knees, respectively, reported that their knee always feels normal $\left(\mathrm{X}^{2}=0.797, p=0.671\right)$.

$\underline{\text { Medial and Non-Medial Pivot Based on the Average COR from } 0^{\circ} \text { to Terminal Flexion }}$

Pivot type could not be determined based on the COR from $0^{\circ}$ to terminal flexion for one TKA. For the remaining 140 knees, the average center of rotation in the full flexion arc ranged from - 1016.7 to $982.9 \mathrm{~mm}$ with positive signifying the medial side. Medial pivot knees comprised $40 \%(56 / 140)$ of the TKAs in this cohort of expanded motion to include terminal flexion.

Patient sex $\left(75 \%\right.$ female, $\left.\mathrm{X}^{2}=0.000, p=1.00\right)$, mean age $(63.7$ years, $\mathrm{t}=0.160, p=0.870)$, median BMI $\left(32.9 \mathrm{~kg} / \mathrm{m}^{2}, \mathrm{~W}=3662.5, p=0.870\right)$, and median length of follow-up $(22.0$ months, $\mathrm{W}=$ 4253.5, $p=0.185$ ) were unrelated to pivot classification. Fifty-one percent of knees with CR/CS anterior-lipped implants were classified as medial pivots compared to $26 \%$ of knees with PS implants $\left(\mathrm{X}^{2}=8.541, p=0.005\right)$. Separate analyses were performed based on implant type to control for the interaction between pivot and implant type.

As shown in Table 2, only one outcome score statistically differed based on pivot type. Patients with CR/CS anterior-lipped implants and medial pivot knees had greater improvement in walking pain (- 
5.5 median points vs. -4 median points in CR/CS non-medial pivot knees, $p=0.020$ ). It is important to note, however, that these patients had significantly higher preoperative pain scores (medians of 7 and 4 points, respectively. $\mathrm{W}=1921.0, p=0.002$ ), and their final follow-up pain scores were not different. Forty-seven percent of patients with CR/CS anterior-lipped implants and medial pivot knees reported that their knee always felt normal compared to $54 \%$ of patients with CR/CS anterior-lipped implants and non-medial pivot knees $\left(\mathrm{X}^{2}=2.220, p=0.330\right)$. Among patients with PS implants, $47 \%$ and $39 \%$ of those with medial pivot and non-medial pivot knees, respectively, reported that their knee always feels normal $\left(\mathrm{X}^{2}=0.701, p=0.697\right)$.

\section{Discussion}

Total knee arthroplasty is a successful procedure which benefits thousands of patients annually.

With the aging baby boomer population and an increase in younger patients indicated for surgery, the number of primary and revision TKAs are expected to drastically increase within the next 20 years.[28] While TKA provides substantial benefits in terms of pain control and function to the majority of patients, our profession has been unable to replicate the nearly universal satisfaction rates seen with total hip arthroplasty. In an enviroment where patient satisfaction and clinical outcomes are increasingly tied to reimbursement and fiscal solvency, improving primary TKA outcomes and minimizing revision burden is paramount.

Traditional surgical prinicples of total knee arthroplasty have not changed significantly in recent years and continue to focus on alignment and ligament balance presupposing that if these two elements were optimized appropriate kinematics and increased patient satifsaction would result. Total knee arthroplasty component characteristics including articular topography and congruence and femoral geometry vary among commercially available implants, however many are designed in the hopes of consistently replicating a medial kinematic pattern based on literature suggesting medial based native knee kinematics. [16-20] 
The modern arthroplasty system utilized in this study was designed to facilitate natural knee

221

222

motion, however, in the hands of two high volume arthroplasty surgeons only $40 \%$ of TKAs were identified to have a medial pivot kinematic pattern during the first $90^{\circ}$ of flexion, and through full/terminal flexion. Significantly more knees with CR/CS anterior-lipped implants were classified as medial pivots compared to knees with PS implants in both ranges of motion $\left(0^{\circ}\right.$ to $90^{\circ}$ and $0^{\circ}$ to terminal flexion). Nishio et al. [21] evaluated intraoperative knee kinematics of 40 PS TKAs using a CT-based computer navigation system and observed that the cohort with medial pivot kinematics averaged across $0^{\circ}$ to $90^{\circ}$ had significantly better subjective outcomes with the new Knee Society Score. In our $0^{\circ}$ to terminal flexion cohort, there were no differences in outcome scores based on pivot type regardless of implant type. In the $0^{\circ}$ to $90^{\circ}$ cohort, most patient-reported outcomes, including Knee Society scores, did not differ in medial and non-medial pivot knees regardless of implant type (CR/CS anterior-lipped implants and PS implants). However, for patients with PS implants, there were trends for greater median improvement in KSSO (46 vs. 31.5 points, $p=0.057$ ) and KSSS (23 vs. 14 points, $p=0.067$ ) in medial pivot knees, although minimum one-year outcomes were not different between groups, potentially obviating the clinical significance of these statistical trends. Nishio et al. [21] observed significantly better KSSS and KSSF, but not KSSO, scores in medial pivot PS knees. Our results using intraoperative sensor-based technology are counter to the most commonly accepted thought regarding the ideal target for post-operative TKA kinematics.

The study has several limitations. Measurements using the tibial sensor were taken intraoperatively with an anesthetized patient during passive motion and incomplete closure of the arthrotomy. There is some support for the hypothesis that intra-operative passive kinematics correlate with postoperative kinematics during weight bearing, [29] but the influence of scarring, healing, and postoperative soft tissue maturate remain an important area for further study. In addition, error terms associated with the tibial sensing device, if applicable, are unknown. While the study group is 
244 comparable to cohort size in relevant kinematic literature, statistical power may be a limitatiion but it is

245 worth noting that group scores were very similar for most outcome metrics.

246 In conclusion, intra-operative medial pivot kinematic patterns were produced in only $40 \%$ of

247 TKA patients utilizing a modern implant designed to facilitate natural knee motion, and these patients

248 did not have significantly improved subjective outcomes when compared to TKAs non-medial pivot

249 kinematic patterns. The results suggest that a medial pivot pattern may not be a substantial governor of

250 clinical success based on intraoperative kinematics and modern outcome measures. The understanding

251 of how alignment and balance relate to kinematics and subsequently how this correlates with patient

252 satisfaction remains in its infancy. Further research is warranted to determine if a particular kinematic

253 pattern promotes optimal clinical outcomes after TKA. 
255

\section{References}

1. Argenson JN, Boisgard S, Parratte S, Descamps S, Bercovy M, Bonnevialle P, Briard JL, Brilhault J, Chouteau J, Nizard R, Saragaglia D, Servien E. Survival analysis of total knee arthroplasty at a minimum 10 years' follow-up: a multicenter French nationwide study including 846 cases. Orthopaedics \& traumatology, surgery \& research : OTSR 99(4): 385, 2013

2. Bachmann M, Bolliger L, Ilchmann T, Clauss M. Long-term survival and radiological results of the Duracon total knee arthroplasty. International orthopaedics 38(4): 747, 2014

3. Bae DK, Song SJ, Park MJ, Eoh JH, Song JH, Park CH. Twenty-year survival analysis in total knee arthroplasty by a single surgeon. The Journal of arthroplasty 27(7): 1297, 2012

4. Feng B, Weng X, Lin J, Jin J, Wang W, Qiu G. Long-term follow-up of cemented fixed-bearing total knee arthroplasty in a Chinese population: a survival analysis of more than 10 years. The Journal of arthroplasty 28(10): 1701, 2013

5. Gothesen O, Espehaug B, Havelin L, Petursson G, Lygre S, Ellison P, Hallan G, Furnes O. Survival rates and causes of revision in cemented primary total knee replacement: a report from the Norwegian Arthroplasty Register 1994-2009. The bone \& joint journal 95-b(5): 636, 2013

6. Guo L, Yang L, Briard JL, Duan XJ, Wang FY. Long-term survival analysis of posterior cruciateretaining total knee arthroplasty. Knee surgery, sports traumatology, arthroscopy : official journal of the ESSKA 20(9): 1760, 2012

7. Huizinga MR, Brouwer RW, Bisschop R, van der Veen HC, van den Akker-Scheek I, van Raay JJ. Long-term follow-up of anatomic graduated component total knee arthroplasty: a 15- to 20-year survival analysis. The Journal of arthroplasty 27(6): 1190, 2012

8. Petursson G, Fenstad AM, Havelin LI, Gothesen O, Lygre SH, Rohrl SM, Furnes O. Better survival of hybrid total knee arthroplasty compared to cemented arthroplasty. Acta orthopaedica 86(6): 714, 2015 
9. Lachiewicz PF, Soileau ES. Fixation, survival and osteolysis with a modern posterior-stabilized total knee arthroplasty. The Journal of arthroplasty 29(1): 66, 2014

10. Ritter MA. The Anatomical Graduated Component total knee replacement: a long-term evaluation with 20-year survival analysis. The Journal of bone and joint surgery British volume 91(6): 745, 2009 11. Vessely MB, Whaley AL, Harmsen WS, Schleck CD, Berry DJ. The Chitranjan Ranawat Award: Long-term survivorship and failure modes of 1000 cemented condylar total knee arthroplasties. Clinical orthopaedics and related research 452: 28, 2006

12. Drexler M, Dwyer T, Chakravertty R, Farno A, Backstein D. Assuring the happy total knee replacement patient. The bone \& joint journal 95-b(11 Suppl A): 120, 2013

13. Dunbar MJ, Richardson G, Robertsson O. I can't get no satisfaction after my total knee replacement: rhymes and reasons. The bone \& joint journal 95-b(11 Suppl A): 148, 2013

14. Scott CE, Howie CR, MacDonald D, Biant LC. Predicting dissatisfaction following total knee replacement: a prospective study of 1217 patients. The Journal of bone and joint surgery British volume 92(9): 1253,2010

15. Dennis DA, Komistek RD, Mahfouz MR, Haas BD, Stiehl JB. Multicenter determination of in vivo kinematics after total knee arthroplasty. Clinical orthopaedics and related research (416): 37, 2003 16. Atzori F, Salama W, Sabatini L, Mousa S, Khalefa A. Medial pivot knee in primary total knee arthroplasty. Annals of Translational Medicine 4(1): 6, 2016

17. Komistek RD, Dennis DA, Mahfouz M. In vivo fluoroscopic analysis of the normal human knee. Clinical orthopaedics and related research (410): 69, 2003

18. Iwaki H, Pinskerova V, Freeman MA. Tibiofemoral movement 1: the shapes and relative movements of the femur and tibia in the unloaded cadaver knee. The Journal of bone and joint surgery British volume 82(8): 1189, 2000 
19. Hill PF, Vedi V, Williams A, Iwaki H, Pinskerova V, Freeman MA. Tibiofemoral movement 2: the loaded and unloaded living knee studied by MRI. The Journal of bone and joint surgery British volume 82(8): 1196, 2000

20. Nakagawa S, Kadoya Y, Todo S, Kobayashi A, Sakamoto H, Freeman MA, Yamano Y.

Tibiofemoral movement 3: full flexion in the living knee studied by MRI. The Journal of bone and joint surgery British volume 82(8): 1199, 2000

21. Nishio Y, Onodera T, Kasahara Y, Takahashi D, Iwasaki N, Majima T. Intraoperative medial pivot affects deep knee flexion angle and patient-reported outcomes after total knee arthroplasty. The Journal of arthroplasty 29(4): 702, 2014

22. Gustke K. Use of smart trials for soft-tissue balancing in total knee replacement surgery. The Journal of bone and joint surgery British volume 94(11 Suppl A): 147, 2012

23. Roche M, Elson L, Anderson C. Dynamic soft tissue balancing in total knee arthroplasty. The Orthopedic clinics of North America 45(2): 157, 2014

24. Noble PC, Scuderi GR, Brekke AC, Sikorskii A, Benjamin JB, Lonner JH, Chadha P, Daylamani DA, Scott WN, Bourne RB. Development of a new Knee Society scoring system. Clinical orthopaedics and related research 470(1): 20, 2012

25. Scuderi GR, Bourne RB, Noble PC, Benjamin JB, Lonner JH, Scott WN. The New Knee Society Knee Scoring System. Clinical orthopaedics and related research 470(1): 3, 2012

26. Amstutz HC, Thomas BJ, Jinnah R, Kim W, Grogan T, Yale C. Treatment of primary osteoarthritis of the hip. A comparison of total joint and surface replacement arthroplasty. The Journal of bone and joint surgery American volume 66(2): 228, 1984

27. Zahiri CA, Schmalzried TP, Szuszczewicz ES, Amstutz HC. Assessing activity in joint replacement patients. The Journal of arthroplasty 13(8): 890, 1998 
324 28. Kurtz S, Ong K, Lau E, Mowat F, Halpern M. Projections of Primary and Revision Hip and Knee 325 Arthroplasty in the United States from 2005 to 2030. The Journal of Bone \&amp; Joint Surgery 89(4): 326780,2007

327 29. Wasielewski RC, Galat DD, Komistek RD. Correlation of compartment pressure data from an 328 intraoperative sensing device with postoperative fluoroscopic kinematic results in TKA patients. Journal 329 of biomechanics 38(2): 333, 2005 
Table 1: Patient-Reported Outcomes by Implant Type and Pivot Classification Based Upon the Average COR from $0^{\circ}$ to $90^{\circ}$ of Flexion

\begin{tabular}{|c|c|c|c|c|c|c|c|c|}
\hline & \multicolumn{4}{|c|}{ CR/CS Anterior-Lipped Implants } & \multicolumn{4}{|c|}{ PS Implants } \\
\hline & $\begin{array}{c}\text { Medial } \\
\text { Pivot Knees }\end{array}$ & $\begin{array}{l}\text { Non-Medial } \\
\text { Pivot Knees }\end{array}$ & $\mathbf{W}$ & $p$ & $\begin{array}{c}\text { Medial } \\
\text { Pivot Knees }\end{array}$ & $\begin{array}{l}\text { Non-Medial } \\
\text { Pivot Knees }\end{array}$ & $\mathbf{W}$ & $p$ \\
\hline $\mathbf{n}$ & 38 & 40 & & & 17 & 44 & & \\
\hline \multicolumn{9}{|c|}{ Minimum One-Year Outcomes } \\
\hline Median KSSO & 97 & 95 & 1045.0 & 0.951 & 97 & 94 & 523.5 & 0.300 \\
\hline Median KSSS & 38 & 37 & 1518.5 & 0.860 & 37 & 30 & 537.5 & 0.326 \\
\hline Median KSSF & 75 & 77 & 1414.0 & 0.937 & 67 & 75 & 406.0 & 0.522 \\
\hline $\begin{array}{l}\text { Median UCLA } \\
\text { Activity Level }\end{array}$ & 5 & 5 & 1524.0 & 0.292 & 4.5 & 5 & 423.5 & 0.326 \\
\hline $\begin{array}{l}\text { Median Pain with } \\
\text { Level Walking }\end{array}$ & 0 & 0 & 1480.0 & 0.813 & 1 & 0 & 533.5 & 0.918 \\
\hline $\begin{array}{l}\text { Median Pain with } \\
\text { Stairs or Inclines }\end{array}$ & 1 & 1 & 1494.5 & 0.950 & 2 & 2 & 507.5 & 0.756 \\
\hline \multicolumn{9}{|c|}{ Improvement in Outcomes } \\
\hline Median KSSO & 39.5 & 46.5 & 989.0 & 0.497 & 46 & 31.5 & 559.5 & 0.057 \\
\hline Median KSSS & 21 & 23 & 1478.5 & 0.825 & 23 & 14 & 569.0 & 0.063 \\
\hline Median KSSF & 37 & 35.5 & 1391.0 & 0.878 & 36 & 37 & 418.5 & 0.772 \\
\hline $\begin{array}{l}\text { Median UCLA } \\
\text { Activity Level }\end{array}$ & 1 & 0 & 1580.5 & 0.101 & 1 & 1 & 452.5 & 0.737 \\
\hline $\begin{array}{l}\text { Median Pain with } \\
\text { Level Walking }\end{array}$ & -5 & -5 & 1427.5 & 0.462 & -4 & -4 & 470.0 & 0.427 \\
\hline $\begin{array}{l}\text { Median Pain with } \\
\text { Stairs or Inclines }\end{array}$ & -6 & & 1363.5 & $\begin{array}{c}0.167 \\
7\end{array}$ & -5 & -4 & 459.0 & 0.330 \\
\hline
\end{tabular}




\begin{tabular}{|c|c|c|c|c|c|c|c|c|}
\hline & \multicolumn{4}{|c|}{ CR/CS Anterior-Lipped Implants } & \multicolumn{4}{|c|}{$\begin{array}{c}\text { PS Implants } \\
\end{array}$} \\
\hline & $\begin{array}{c}\text { Medial } \\
\text { Pivot Knees }\end{array}$ & $\begin{array}{l}\text { Non-Medial } \\
\text { Pivot Knees }\end{array}$ & $\mathbf{W}$ & $p$ & $\begin{array}{c}\text { Medial } \\
\text { Pivot Knees }\end{array}$ & $\begin{array}{l}\text { Non-Medial } \\
\text { Pivot Knees }\end{array}$ & $\mathbf{W}$ & $p$ \\
\hline n & 40 & 39 & & & 16 & 45 & & \\
\hline \multicolumn{9}{|c|}{ Minimum One-Year Outcomes } \\
\hline Median KSSO & 96.0 & 98.0 & 1021.0 & 0.489 & 95.0 & 95.0 & 361.0 & 0.738 \\
\hline Median KSSS & 36.0 & 38.0 & 1436.5 & 0.097 & 37.0 & 30.0 & 523.5 & 0.459 \\
\hline Median KSSF & 76.0 & 71.5 & 1550.5 & 0.366 & 75.0 & 68.0 & 433.5 & 0.880 \\
\hline $\begin{array}{l}\text { Median UCLA } \\
\text { Activity Level }\end{array}$ & 6.0 & 4.0 & 1671.5 & 0.118 & 5.0 & 5.0 & 425.0 & 0.660 \\
\hline $\begin{array}{l}\text { Median Pain with } \\
\text { Level Walking }\end{array}$ & 0.0 & 0.0 & 1712.5 & 0.207 & 0.5 & 1.0 & 487.0 & 0.882 \\
\hline $\begin{array}{l}\text { Median Pain with } \\
\text { Stairs or Inclines }\end{array}$ & 1.0 & 1.0 & 1717.0 & 0.234 & 1.0 & 2.0 & 448.0 & 0.427 \\
\hline \multicolumn{9}{|c|}{ Improvement in Outcomes } \\
\hline Median KSSO & 49.0 & 41.0 & 1174.5 & 0.172 & 40.0 & 39.5 & 390.5 & 0.695 \\
\hline Median KSSS & 22.0 & 22.0 & 1626.0 & 0.802 & 20.0 & 16.0 & 501.5 & 0.510 \\
\hline Median KSSF & 38.0 & 33.5 & 1496.5 & 0.732 & 36.0 & 37.0 & 415.0 & 0.724 \\
\hline $\begin{array}{l}\text { Median UCLA } \\
\text { Activity Level }\end{array}$ & 1.0 & 0.0 & 1635.5 & 0.238 & 0.0 & 1.0 & 408.5 & 0.546 \\
\hline $\begin{array}{l}\text { Median Pain with } \\
\text { Level Walking }\end{array}$ & -5.5 & -4.0 & 1364.0 & 0.020 & -4.5 & -4.0 & 434.0 & 0.367 \\
\hline $\begin{array}{l}\text { Median Pain with } \\
\text { Stairs or Inclines }\end{array}$ & -6.0 & -6.0 & 1590.0 & 0.952 & -5.0 & -4.0 & 430.0 & 0.334 \\
\hline
\end{tabular}




\section{Figure Legends}

Figure 1: Intraoperative measurements with embedded sensor tibial trial showing graphic user interface identifying loading contact points and peak loading forces (in lbs.) in the medial and lateral compartments.

Figure 2: Cropped images of embedded sensor tibial trial were imported into MATLAB $®$ to identify loading contact points and calculate center of rotation values for pivot groupings. Figure 3: Overlay of vector equations and trial tibial insert used to calculate center of rotation values to group patients into medial or non-medial cohorts.

Figure 4: Proportion of patients reporting that there TKA always, sometime, or never feels normal by implant and pivot type. 


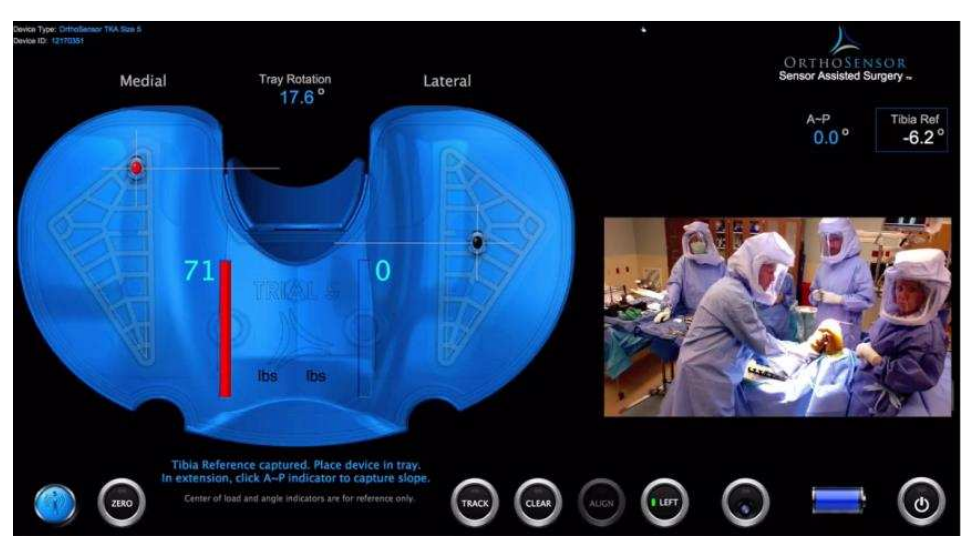




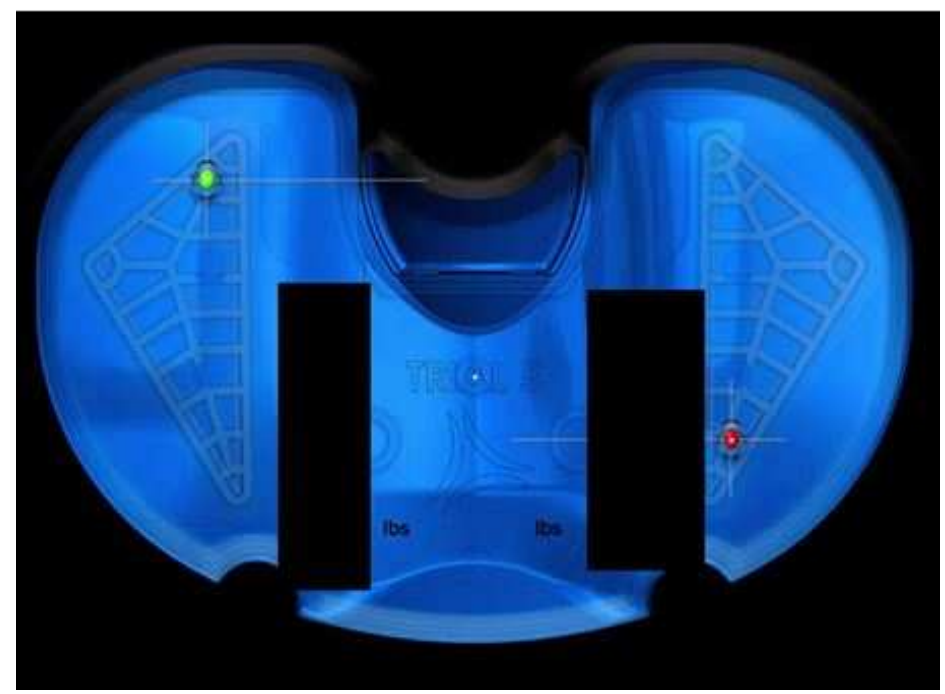




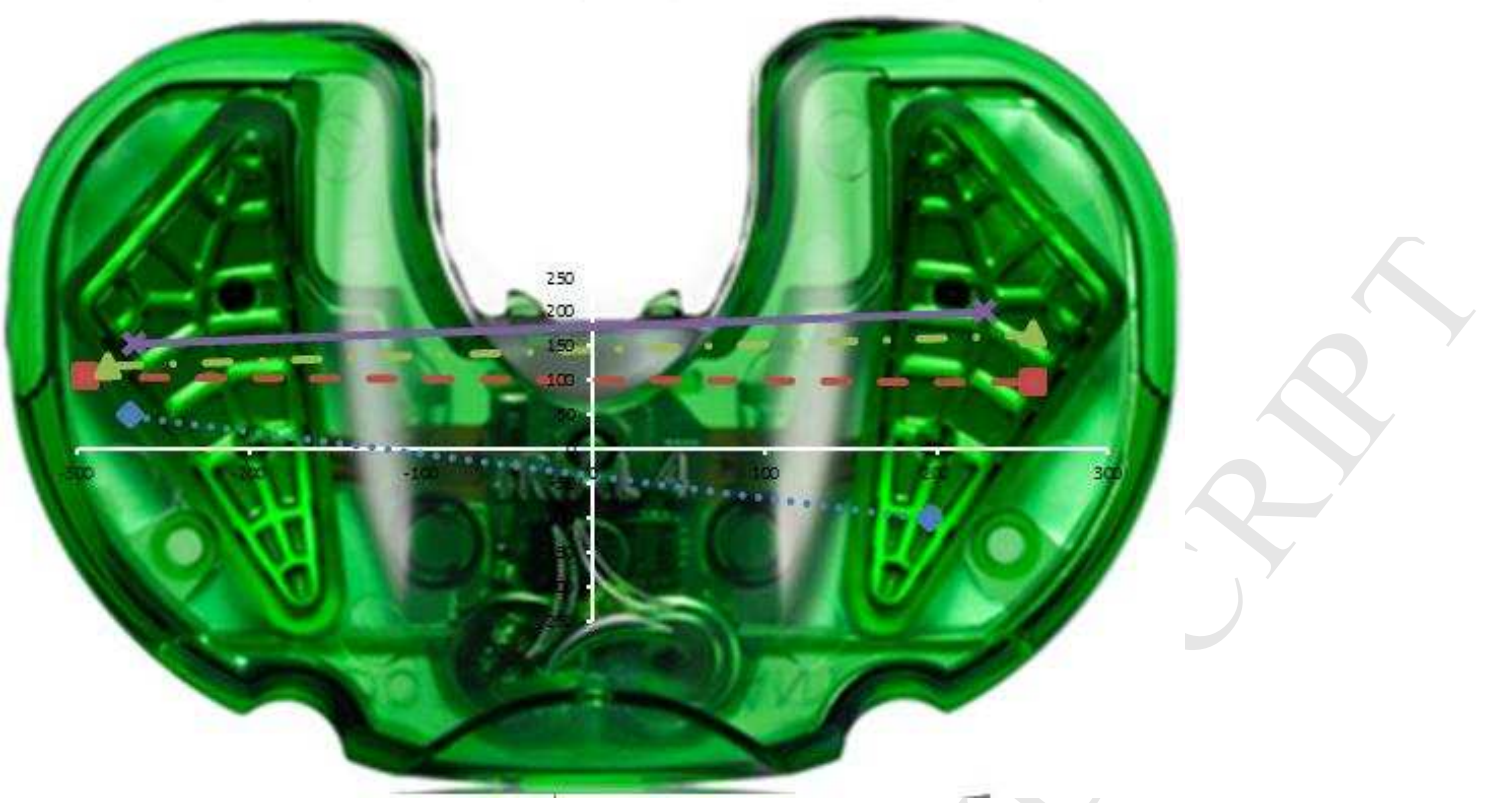




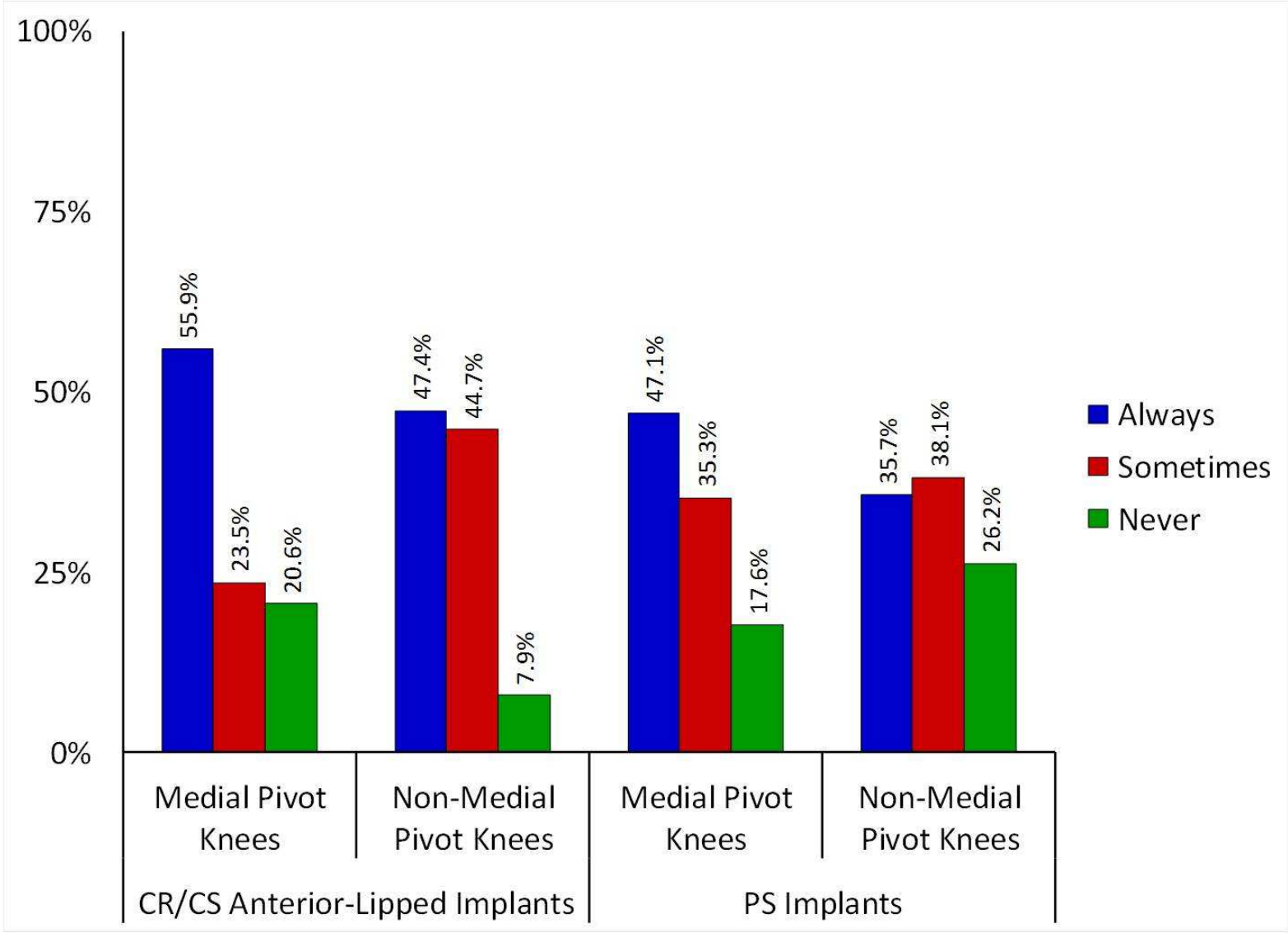

